\title{
The influence of expansion control device used during production of different extruded sea bass feeds on pellets quality
}

\author{
A. Kop ${ }^{1}$ and A.Y. Korkut
}

Ege University, Faculty of Fisheries, Department of Aquaculture, TR-35100 Izmir, Turkey

KEY WORDS: fish feeding, pellets, expansion, extrusion, feed evaluation

Received: 10 November 2016

Revised: $\quad 23$ March 2017

Accepted: 10 June 2017

${ }^{1}$ Corresponding author:

e-mail: ayskop@gmail.com

\begin{abstract}
In this study, the effects of expansion control devices (ECD) used in the production of extruded fish feed pellets were investigated. Five types of experimental sea bass feed with different pellets diameter $(3,4,5,6$ and $9 \mathrm{~mm}$ for S3, S4, S5, S6 and S9, respectively) based on commercial formulations (lower total vegetable ingredients but higher starch and protein amount in S3 feed) were produced without or with the usage of ECD during extrusion process. The pellets quality was compared based on: pellets diameter size, pellet hardness, pellet durability, sink rate, after-extruder density, after-cooler density, moisture, loss quantity measurements and physical appearance. The obtained results showed that the pellets produced with ECD had lower diameters except for S3 feeds. The sink rate, and after-extruder and after-cooler densities were higher, and loss quantity was reduced in pellets produced with ECD regardless pellets size. There were less dusty and cracked pellets in feeds produced with ECD. It can be concluded that the ECD could be successfully used in the production of extruded fish pellets contributing to lower production costs.
\end{abstract}

\section{Introduction}

The high-temperature-short-time $\left(110-204{ }^{\circ} \mathrm{C} /\right.$ $10-20$ s) extrusion cooking technology is usually used in the production of the aquaculture feeds (Hardy and Barrows, 2002; Glencross and Hawkins, 2007; Sørensen et al., 2009). The advantages of such thermal treatment as extrusion comprise: achievement of a desired physical form, inactivation of some antinutritional factors (Melcion and van der Poel, 1993), prolonged shelf-life, increased nutrient digestibility and enhanced palatability. In addition, the starch is gelatanized during the extrusion and in effect becomes more digestible for enzymes of carnivore fish (Bergot and Breque, 1983; Murray et al., 2001).
In the extrusion system, raw feed ingredients are exposed to the high temperature and pressure on mechanical shear tension in the screw-barrel assembly. The feed ingredient which is extruded takes shape from the die of end of the extruder's barrel. However, the expansion is seen while passing from the high pressure inside the barrel to the atmospheric pressure. This effect causes such alterations in the feed as: changes in bulk density, affected sink rate, differentiation of feed size, changes in feed hardness, endurance to the water and decreased stability. For example, the diameter of the pellets changes due to the expansion effect. For this reason, these pellets, which are larger than the fish mouths, can't be eaten. On the other hand, sinking pellets which are not consumed 
and remain at the bottom of the tank lead to environmental pollution and economical waste.

The expansion on the exit of extruder machine affects also the bulk density. There is an inverse ratio between the expansion and bulk density. Expansion also affects the floating/sinking relationship of extruded feed ingredient. According to the Rout and Bandyopadhyay (1999), the ratio of expansion is inversely proportional to the density and sink rate of feed as feeds produced with the low expansion range had the highest density. Therefore, it is necessary to keep the low rate of expansion in the feed production process. ECD are used for this purpose. Using such device, the pressure outside the mould is under control and so, the lower expansion ratio is gained.

The ratio of the expansion inside the barrels is affected by other factors and is also changed according to the liquidity degree. The amount of soluble protein and starch in feed ingredients exerts positive influence on the expansion process, whereas the amount of fat - negative (Onwulata et al., 2001; Chang and El-Dash, 2003; Rokey and Plattner, 2004; Glencross and Hawkins, 2007; Sørensen, 2007). Various plants products, such as soyabean meal, maize and wheat flour, are used during the production of fish feed as protein sources. So, almost all studies are focused on soyabean (Glycine max) meal - the most commonly used plant protein in aquaculture feeds (Kaushik et al., 1995; Robaina et al., 1995; Kissil et al., 2000; Refstie et al., 2001). Starch, which is a major constituent of cereal grains, is the main energy source for animals. During the extrusion, starch gelatinization is crucial since it affects feed digestibility and expansion volume and also contributes to water stability. Thus, starch may have binding properties in pelleted feeds. The role of extrusion process variables on the expansion volume of cereals or starches has been already investigated (Faubion et al., 1982; Meuser et al., 1982; Launay and Lisch, 1983; Owusu-Ansah et al., 1983; Chinnaswamy and Hanna, 1988; Lai and Kokini, 1991; Jeong et al., 1991; Arhaliass et al., 2009).

Understanding the relationships between the feed ingredients, process parameters, equipment design and operation system is necessary to achieve the product of desired quality and to create the possibility to develop new products (Noel et al., 1990; Aguilera and Stanley, 1999; Rosentrater et al., 2009).

The aim of this study was to determine the effects of ECD usage on the quality of the fish feed pellets obtained in the extrusion process. Five types of experimental sea bass feed with different pellet diameter sizes $(3,4,5,6$ and $9 \mathrm{~mm}$ for $\mathrm{S} 3, \mathrm{~S} 4$, S5, S6 and S9, respectively) based on commercial formulations (lower total vegetable ingredients but higher starch and protein amount in S3 feed) were produced without or with the usage of ECD during extrusion process.

\section{Material and methods}

\section{Production of experimental diets}

Five types of sea bass feed with different sizes ( $\mathrm{S} 3-3 \mathrm{~mm}$, as starter feed for juvenile; $\mathrm{S} 4-4 \mathrm{~mm}$; $\mathrm{S} 5-5 \mathrm{~mm}$; $\mathrm{S} 6-6 \mathrm{~mm}$; $\mathrm{S} 9-9 \mathrm{~mm}$, as grower feeds for breeders) based on commercial formulations were examined. In S3 type feed, which is dedicated for juvenile, the amount of total vegetable ingredients was $31.9 \%$ and starch $-6.9 \%$. In other feed types the amounts were $42 \%$ and $9.49 \%$, respectively (Table 1). During production of all feeds, the same process stages were used with ECD or without such device (normal, N). The obtained feeds were examined to measure the physical quality differences.

Table 1. Formulation and chemical composition of examined feeds

\begin{tabular}{|c|c|c|c|c|c|}
\hline \multirow{2}{*}{ Indices } & \multicolumn{5}{|c|}{ Feed type $^{1}$} \\
\hline & S3 & S4 & S5 & S6 & S9 \\
\hline \multicolumn{6}{|l|}{ Ingredients, $\%$} \\
\hline wheat meal & 9.5 & 9.5 & 9.5 & 9.5 & 9.5 \\
\hline wheat gluten meal & 2 & 1.5 & 1.5 & 1.5 & 1.5 \\
\hline steam dried fish meal & 49 & 40 & 40 & 40 & 40 \\
\hline full-fat soyabean meal & 4.7 & 7.8 & 7.8 & 7.8 & 7.8 \\
\hline maize gluten meal & 9.4 & 9.1 & 9.1 & 9.1 & 9.1 \\
\hline soyabean meal & 6.3 & - & - & - & - \\
\hline $\begin{array}{l}\text { soyabean meal solvent } \\
\text { (48\% protein) }\end{array}$ & - & 14.1 & 14.1 & 14.1 & 14.1 \\
\hline fish oil & 14 & 14 & 14 & 14 & 14 \\
\hline vitamin-mineral premix² & 5.1 & 4 & 4 & 4 & 4 \\
\hline Total vegetable ingredient, $\%$ & $6 \quad 31.9$ & 42 & 42 & 42 & 42 \\
\hline \multicolumn{6}{|l|}{ Chemical composition } \\
\hline crude protein, $\%$ & 47 & 45 & 45 & 45 & 45 \\
\hline crude fat, $\%$ & 18 & 20 & 20 & 20 & 20 \\
\hline cellulose, \% & 2 & 2.5 & 2.5 & 2.5 & 2.5 \\
\hline starch, \% & 6.90 & 9.49 & 9.49 & 9.49 & 9.4 \\
\hline total energy, kcal & 5000 & $5250 \quad 5$ & 5250 & 5250 & 5250 \\
\hline
\end{tabular}

${ }^{1}$ feed types according to particle size: 3, 4, 5, 6 and $9 \mathrm{~mm}$, for S3, S4, $\mathrm{S} 5, \mathrm{~S} 6$ and S9, respectively; ${ }^{2}$ vitamin-mineral premix content per $\mathrm{kg}$ of diet: IU: retinol 15000 , calciferol 2000; mg: alpha tocopherol 300 , menadion sodio bis 16.6 , thiamin 12.5 , riboflavin 12.5 , Ca pantothenate 33.3 , nicotinic acid 116.7, pyridoxine 8.3 , folic acid 4.2 , cyanocobalamin 0.04 , biotin 0.5 , ascorbic acid 250 , inositol 250 , cobalt sulphate 1.91 , copper sulphate 19.6 , iron sulphate 200 , sodium fluoride 2.21 , potassium iodide 0.78 , magnesium oxide 830 , manganese oxide 26 , sodium selenite 0.66 , zinc oxide 37.5 ; g: dicalcium phosphate 8.02 , potassium chloride 1.15 , sodium chloride 0.44 
The production process took place in a commercial fish feed company. Extruder machine had 4 ton $\cdot \mathrm{h}^{-1}$ capacity and it was single screwed type. The used parameters were as follows: $80 \mathrm{~kg} \cdot \mathrm{h}^{-1}$ steaming in the preconditioner, and $400 \mathrm{~kg} \cdot \mathrm{h}^{-1}$ water in the barrels. So, the pressure at the last barrel was $8-10$ bars. The ECD used in the test had $0.8-1$ bar air pressure and $7 \mathrm{~kW}$ motor power.

\section{Analysis of feed}

Physical appearance. The features of extruded feed such as outer surface appearance, shape of feed, homogeneity, crumbling, broken-fracture pellets, colour, smell, dust and size/length balance were controlled.

The diameter size of pellets was measured with the electronic calipers (Starret EC799A-6/15, Athol, MA, USA) with $0.05-\mathrm{mm}$ sensitivity. The values are expressed as the average of 60 pellets for each feed.

The hardness was measured in a pellet crusher (Amandus Kahl GmbH \& Co. KG, Reinbek, Germany). Twelve pellets of different sizes were placed individually in a pellet crusher and the pressure that disintegrated pellets was recorded. Sixty pellets of each feed were examined.

Durability was measured in a Holmen Pellet Tester (Borregard Lignotech, Hull, UK). About $100 \mathrm{~g}$ of sieved pellets was hold on the quickly circulating air. At the end of the process, the proportion between amounts of the pellets which remain their form to the whole weight of sample at the beginning was calculated as durability level (Winowiski, 1995). The analysis was conducted in triplicate for each feed type. The results are expressed as \%.

Moisture was measured with the use of the moisture analyser (MA150, Sartorius, Göttingen, Germany). The feeds samples were squeezed and about $5 \mathrm{~g}$ was placed in the analyser. The process was done in triplicate for each feed and the values are expressed as $\%$.

Sink rate. Sixty pellets of each feed were cooled and placed in water with $12 \%$ salinity and $4{ }^{\circ} \mathrm{C}$ temperature. The number of pellets which sank during $15 \mathrm{~s}$ was determined. The analysis was done in triplicate for each type of feed. The result is expressed as $\%$.

Bulk density. The feed samples collected from the extruder die were cooled and placed in the 1-litre cylindrical cup to measure density in the precise analytical balance (TE64, Sartorius Göttingen, Germany). The process was done in triplicate for each feed and the values are expressed as $\mathrm{g} \cdot 1^{-1}$ (Sørensen et al., 2009).
The amount of loss. At the beginning of the process, the weight of all raw materials to be used in feed production was measured. Then feed particles and dusts were collected from the extruder outlet, sieves, conveyor belts and their weights were measured (TE64, Sartorius, Göttingen, Germany). Particles and dust weight was removed from the initial raw material weight. The result was divided into the production tonnage of the extruder system and loss ratio is expressed as \%. Samples were collected after the production of each feed group.

\section{Statistical analysis}

Separately for each feed type (S3, S4, S5, S6 and S9) the results obtained for normal process and process with ECD were compared with the use of Student t-test.

For the comparison between feed types (separately for ECD and normal process) either ANOVA or Kruskal-Wallis test was used. Selection of the test was conditional upon the fulfilment of the ANOVA test assumptions. Normal distribution of all data was determined by the Kolmogorov-Smirnov test. The homogeneity of all data was tested with the Levene test. After this step, homogeneity and normality were only seen in feed loss so this parameter was tested with ANOVA. Transformed to provide normality and homogeneity for other variables, but no assumptions were met. Therefore, other variables were tested with the Kruskal-Wallis test.

All the statistical analyses were conducted using Statistical Package for Social Science (SPSS for Windows, ver 15.0; IBM, Armonk, NY, USA) and differences were considered statistically significant at $P<0.05$.

\section{Results}

Physical appearance. According to the visual physical analysis, the product gained from the production with ECD had no breaks or fractures. Such pellets had shiny appearance. In case of normal production, pellets were generally dusty, mat, with breaks and fractures.

Pellets diameter size. Outer diameters of all sample feeds were suitable for the assumed size of pellets. However, the usage of ECD in the production positively affected size of feeds reducing pellets diameter size in groups S4, S5, S6, and S9 $(P<0.05$ for all these groups, Student t-test). Only in group S3 such effect was not observed (Table 2). 


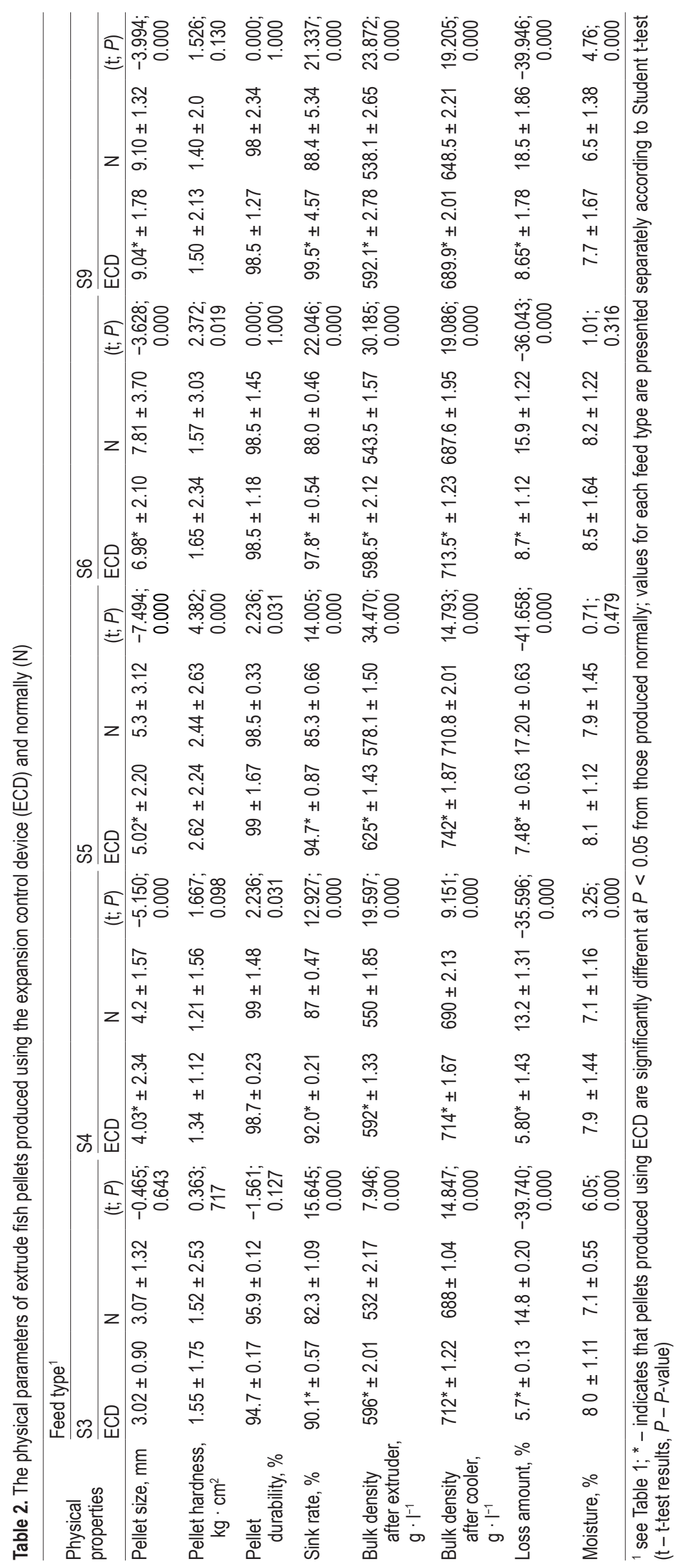


Hardness and durability of pellets. There was observed no influence of ECD usage on pellets hardness and durability regardless pellets size. When different feed types produced with ECD usage were compared, the highest value of pellet hardness was found in group S5 $(P<0.05$, Kruskal-Wallis test).

Moisture. Statistical comparison of the ECD and normal production processes reveals that the moisture content was decreased in groups $\mathrm{S} 3, \mathrm{~S} 4$ and $\mathrm{S} 9(P<0.5$ according to Student t-test $)$, no such effect was found in group S5 and S6 (Table 2).

Sink rate. The introduction of ECD in the production process caused the increased sink rate regardless pellets size $(P<0.5$ for all groups, Student t-test) (Table 2).

Bulk density. According to the both measurements performed on pellets collected at the exit of the extruder and at the exit of the cooler, in all feed types the production process with ECD caused higher densities in comparison with the normal production ( $P \leq 0.05$ for all groups, Student t-test) (Table 2).

The highest density after cooling was found in $5 \mathrm{~mm}$ sea bass feed obtained in the production process with ECD $\left(742 \mathrm{~g} \cdot \mathrm{l}^{-1}\right)$. The lowest one was found in $9 \mathrm{~mm}$ sea bass feed obtained in the production process without ECD $\left(648.5 \mathrm{~g} \cdot \mathrm{1}^{-1}\right)$.

Loss amount. For each feed type, the production with ECD caused lower loss amount $(P<0.05$ for all groups, Student t-test) (Table 2).

\section{Discussion}

According to many researchers the main factors affecting quality of the pellets in extruded fish feeds are colour, pellet dimension, bulk density, water absorption, hardness and durability of pellets, sink rate and loss amount (Hansen and Storebakken, 2007; Sørensen, 2007; Rosentrater et al., 2009). The physical appearance of the feed is an important feature that affects the customers. In the present study, the most important feature of feed produced with ECD was shiny colour of pellets.

Previous studies have also shown that feed diameter is related to the physical quality of the pellets. Vegetable ingredients contain starch that cause further expansion. This leads to an increase in feed diameters (Thomas and van der Poel, 1996; Chen et al., 1999; Sørensen et al., 2009). In the study by Rokey et al. (2010) it has been shown that expanded pet and aquatic feeds will often expand by more than $50 \%$ of the die opening. The degree of expansion is positively affected by the level of starch and soluble protein and negatively - by the level of fat in the formulation. The reason of the significant differences among the other feed groups (S4, S5, S6 and S9), except for group S3, may be related to the amount of total plant protein content used in these feed groups. While the amounts of vegetable ingredient and starch in S3 feed were $31.9 \%$ and $6.90 \%$, respectively, in other groups these values were $42 \%$ and $9.49 \%$, respectively.

The hardness of fish pellets should be high to prevent dust formation and crushing during storage and transportation. The production of hard and durable pellets will reduce the amount of feed loss. Moreover, the stability of the feed in water depends on the pellet hardness. In this way, a high feed conversion ratio and efficiency of production are provided. It is claimed that hardness and durability of the pellets are parallel to the increasing level of cellulose in feed (Breen et al., 1977; Wood, 1987; Cavalcanti and Behnke, 2005; Hansen and Storebakken, 2007). Similarly, some findings indicate that usage of both toasted and untoasted soyabean in feed positively affects the durability and hardness of feed (Wood, 1987; Cavalcanti and Behnke, 2005). Also, reduction in particle size improves gelatinization ratio, increases pellet durability and water stability (Obaldo, 1998). For this reason, in this study, the amount of cellulose $(2 \%)$ in the group S3 positively affected the durability and pellet hardness. In the case of other groups, although pellet diameter changes between $4-9 \mathrm{~mm}$, $2.5 \%$ raw cellulose ratio provided the durability and hardness of the pellets. Therefore, the obtained results indicate that ECD has no effect on the durability of pellets. In comparison with normal production, ECD is considered to have statistically neutral effect on the cellulose content in feeds.

According to Pérez-Navarrete et al. (2006) moisture content depends on both the temperature reached during processing and raw material moisture. The second is vital when feed is not properly packed - the excessive moisture content can lead to fairly rapid deterioration. Huber (2001) reported the value of moisture content for expanded products as $10-20 \mathrm{~g} \cdot \mathrm{kg}^{-1}$. The results of present study show that the moisture content of S3, S4 and S9 groups produced by ECD is higher than in normal production. This result shows that the water content in the feed is reduced due to the high expansion rate during normal production operations.

Density in bulk affects floating and sinking capability of feed. The value for the bulk density in the sinking feed is $1000-1200 \mathrm{~g} \cdot \mathrm{dm}^{3}$ and it is 900-1000 $\mathrm{g} \cdot \mathrm{dm}^{3}$ for the floating feed (Lucht, 2001). To increase the density in bulk, increasing the oil level and feeding rate of extruder, decreasing thermal energy inputs and increasing the moisture level up to $26 \%$ are necessary (Lindley, 2005). Bulk density 
changes depend on density of the used ingredients in the formulation. If the starch level increases, the density in bulks decreases. The sink ratio of feed produced with Press-Pellet technology is higher than of the feed produced with extruder technology. However, according to these study, bulk density and so sink rate of feed can be controlled by using ECD.

The expansion rate of the pellets is very important for the amount of feed loss. Pellets expanding above the desired ratio can be broken up at the exit of the extruder, in the conveyor belts or in the dryer. As a result, the feed production is carried out in lesser quantities than expected. This leads to both excessive energy usage and wear of machines. It was observed that the amount of loss for all feed groups fell when the production was made with ECD.

\section{Conclusions}

The usage of expansion control device during fish feed production process was found to have a positive effect on feed quality. On the other hand, more experiments are needed with more diversified raw material composition to get more detailed answers concerning the best process conditions in the case of sea bass feed production.

\section{Acknowledgements}

We thank Assoc. Prof. Dr Hulya Saygi for her valuable help in statistical analysis.

\section{References}

Aguilera J.M., Stanley D.W., 1999. Microstructural Principles of Food Processing and Engineering. ${ }^{\text {nd }}$ Edition. Aspen Publishers, Inc. Gaithersburg, MD (USA)

Arhaliass A., Legrand J., Vauchel P., Fodil-Pacha F., Lamer T., Bouvier J.-M., 2009. The effect of wheat and maize flours properties on the expansion mechanism during extrusion cooking. Food Bioprocess Technol. 2, 186-193, https://doi. org/10.1007/s11947-007-0038-6

Breen M.D., Seyam A.A., Banasik D.J., 1977. The effect of mill byproducts and soy protein on the physical characteristics of expanded snack foods. Cereal Chem. 54, 728-736

Bergot $F$., Breque I., 1983. Digestibility of starch by rainbow trout: Effects of the physical state of starch and of the intake level. Aquaculture 34, 203-212, https://doi.org/10.1016/0044-8486(83)90203-X

Cavalcanti W.B., Behnke K.C., 2005. Effect of composition of feed model system on pellet quality: a mixture experimental approach. I. Cereal Chem. 82, 455-461, https://doi.org/10.1094/CC-820455

Chang Y.K., El-Dash A.A., 2003. Effects of acid concentration and extrusion variables on some physical characteristics and energy requirements of cassava starch. Braz. J. Chem. Eng. 20, 129-137, https://doi.org/10.1590/S0104-66322003000200006
Chen Y.-S., Beveridge M.C.M., Telfer T.C., 1999. Physical characteristics of commercial pelleted Atlantic salmon feeds and consideration of implications formodeling of waste dispersion through sedimentation. Aquac. Int. 7, 89-100, https://doi. org/10.1023/A:1009249721787

Chinnaswamy R., Hanna M.A., 1988. Relationship between amylose content and extrusion-expansion properties of corn starches. Cereal Chem. 65, 138-143

Faubion J.M., Hoseney R.C., Seib P.A., 1982. Functionality of grain components in extrusion. Cereal Foods World 27, 212-216

Glencross B., Hawkins W., 2007. Feed grains, aquafeeds and extrusion. In: B.D. Glencross (Editor). Proceedings of a workshop: Harvesting the Benefits of Grain in Aquaculture Feeds. Fisheries Occasional Publications No. 41. Department of Fisheries. Fremantle (Western Australia), pp. 75-81

Hansen J.Ø., Storebakken T., 2007. Effects of dietary cellulose level on pellet quality and nutrient digestibilities in rainbow trout (Oncorhynchus mykiss). Aquaculture 272, 458-465, https:// doi.org/10.1016/j.aquaculture.2007.09.005

Hardy R.W., Barrows F.T., 2002. Diet formulation and manufacture. In: J.E. Halver, R.W. Hardy (Editors). Fish Nutrition. Academic Press. San Diego, CA (USA), pp. 505-600

Huber G., 2001. Snack foods from cooking extruders. In: E. Lusas, L. Rooney (Editors). Snack Foods Processing. Technomic Publishing, Lancaster, PA (USA), pp. 315-368

Jeong K.-S., Takeuchi T., Watanabe T., 1991, Improvement of nutritional quality of carbohydrate ingredients by extrusion process in diets of red sea bream. Nippon Suisan Gakkaishi 57, 1543-1549, https://doi.org/10.2331/suisan.57.1543

Kaushik S.J., Cravedi J.P., Lalles J.P., Sumpter J., Fauconneau B., Laroche M., 1995. Partial or total replacement of fish meal by soybean protein on growth, protein utilization, potential estrogenic or antigenic effects, cholesterolemia and flesh quality in rainbow trout, Oncorhynchus mykiss. Aquaculture 133, 257-274, https://doi.org/10.1016/0044-8486(94)00403-B

Kissil G.W., Lupatsch I., Higgs D.A., Hardy R.W., 2000. Dietary substitution of soy and rapeseed protein concentrates for fish meal, and their effects on growth and nutrient utilization in gilthead seabream Sparus aurata L. Aquac. Res. 31, 595-601, https:// doi.org/10.1046/j.1365-2109.2000.00477.x

Lai L.S., Kokini J.L., 1991. Physicochemical changes and rheological properties of starch during extrusion (a review). Biotechnol. Prog. 7, 251-266, https://doi.org/10.1021/bp00009a009

Launay B., Lisch J.M., 1983. Twin-screw extrusion cooking of starches: Flow behavior of starch pastes, expansion and mechanical properties of extrudates. J. Food Eng. 2, 259-280, https://doi. org/10.1016/0260-8774(83)90015-8

Lindley N., 2005. Density control in extruded aquaculture feeds. ASA Aquaculture Workshop. Izmir (Turkey), pp. 44

Lucht W.H., 2001. The importance of product density in the production of fish feed. Feedtech (Germany) 5, 31-33

Melcion J.-P., van der Poel A.F.B., 1993, Process technology and antinutritional factors: principles, adequacy and process optimization. In: A.F.B. van der Poel, J. Huisman, H.S. Saini (Editors). Recent Advances of Research in Antinutritional Factors in Legume Seeds. Pudoc Wageningen. Wageningen (the Netherlands), pp. 419-434

Meuser F., Lengerich B.V., Köhler F., 1982. The influence of extrusion parameters on the functional properties of wheat starch (in German). Starch/Stärke 34, 366-372, https://doi.org/10.1002/ star. 1982034110 
Murray S.M., Flickinger E.A., Patil A.R., Merchen N.R., Brent J.L., Fahey G.C., 2001. In vitro fermentation characteristics of native and processed cereal grains and potato starch using ileal chyme from dogs. J. Anim. Sci. 79, 435-444, https://doi. org/10.2527/2001.792435x

Noel T.R., Ring S.G., Whittam W.A., 1990. Glass transitions in lowmoisture foods. Trends Food Sci. Technol. 1, 62-67, https:// doi.org/10.1016/0924-2244(90)90048-4

Obaldo L.G., Dominy W.G., Terpstra J., Cody J., Behnke K.C., 1998. Does Size Matter? Aqua Feed Jan.-Feb., 29-32

Onwulata C.I., Konstance R.P., Smith P.W., Holsinger V.H., 2001. Coextrusion of dietary fiber and milk proteins in expanded corn products. LWT - Food Sci. Technol. 34, 424-429, https://doi. org/10.1006/fstl.2000.0742

Owusu-Ansah J., van de Voort F.R., Stanley D.W., 1983. Physicochemical changes in cornstarch as a function of extrusion variables. Cereal Chem. 60, 319-324

Pérez-Navarrete C., González R., Chel-Guerrero L., BetancurAncona D., 2006. Effect of extrusion on nutritional quality of maize and Lima bean flour blends. J. Sci. Food Agric. 86, 2477-2484, https://doi.org/10.1002/jsfa.2661

Refstie S., Storebakken T., Baeverfjord G., Roem A.J., 2001. Longterm protein and lipid growth of Atlantic salmon (Salmo salar) fed diets with partial replacement of fish by soy protein products at medium or high lipid level. Aquaculture 193, 91-106, https://doi.org/10.1016/S0044-8486(00)00473-7

Robaina L., Izquierdo M.S., Moyano F.J., Socorro J., Vergara J.M., Montero D., Fernández-Palacios H., 1995. Soybean and lupin meals as protein sources in diets for gilthead seabream (Sparus aurata): nutritional and histological implications. Aquaculture 130, 219-233, https://doi.org/10.1016/00448486(94)00225-D
Rokey G., Plattner B., 2004. Extrusion and other terminal agglomeration technologies. In: Feed Pelleting Reference Guide. WATT Global Media and Kansas State University (USA), available at: http://baltivet.com/files/1214/1709/4495/1-2_Extrusion.pdf

Rokey G. J., Plattner B., De Souza E.M., 2010. Feed extrusion process description. R. Bras. Zootec. 39, 510-518

Rosentrater K.A., Muthukumarappan K., Kannadhason S., 2009. Effects of ingredients and extrusion parameters on properties of aquafeeds containing DDGS and corn starch. J. Aquac. Feed Sci. Nutr. 1, 44-60

Rout R.K., Bandyopadhyay S., 1999. A comparative study of shrimp feed pellets processed through cooking extruder and meat mincer. Aquac. Eng. 19, 71-79, https://doi.org/10.1016/ S0144-8609(98)00034-X

Sørensen M., 2007. Ingredient formulation and extrusion processing parameters interferes with nutritional and physical quality of aqua feeds. Feed Technol. Update 2, 17-20, available at: http://www.aquafeed.com/newsletter_pdfs/nl_000293.pdf

Sørensen M., Stjepanovic N., Romarheim O.H., Krekling T., Storebakken T., 2009. Soybean meal improves the physical quality of extruded fish feed. Anim. Feed Sci. Technol. 149, 149-161, https://doi.org/10.1016/j.anifeedsci.2008.05.010

Thomas M., van der Poel A.F.B., 1996. Physical quality of pelleted animal feed 1. Criteria for pellet quality. Anim. Feed Sci. Technol. 61, 89-112, https://doi.org/10.1016/0377-8401(96)00949-2

Winowiski T.S., 1995. Pellet quality in animal feeds. American Soybean Association Technical Bulletin (MITA (P) NO. 195/11/95 (Vol. FT21-1995)). Available at: http://www.adiveter.com/ ftp_public/articulo1476.pdf

Wood J.F., 1987. The functional properties of feed raw materials and their effect on the production and quality of feed pellets. Anim. Feed Sci. Technol. 18, 1-17, https://doi.org/10.1016/03778401(87)90025-3 